\title{
Da psicologia cognitiva à cognição musical: um olhar necessário para a educação musical
}

\author{
Alexandre Meirelles \\ Tania Stoltz \\ Valéria Lüders \\ (UFPR)
}

\begin{abstract}
Resumo: O presente artigo é um estudo bibliográfico que aborda como o domínio de conhecimento da música foi influenciado pela psicologia cognitiva, formando a disciplina de psicologia da música, ou como alguns autores denominam cognição musical. Esta recente aproximação trouxe certa interdisciplinaridade proporcionando avanços na compreensão de como a mente humana relaciona-se com a música. Aborda-se também neste texto como recentes pesquisas em cognição musical podem contribuir para a educação musical e para a educação como um todo. Nesse sentido, a literatura tem apontado a influência sociocultural no aprendizado informal e no desenvolvimento de habilidades cognitivas multimodais no que tange a educação musical formal. Conclui-se que a educação musical deve levar em conta os avanços das ciências cognitivas integrando e repensando novas formas de ensino que abarquem a cognição como um todo.
\end{abstract}

Palavras-chave: música; psicologia da música; educação musical.

FROM COGNITIVE PSYCHOLOGY TO MUSIC COGNITION: A LOOK REQUIRED FOR MUSIC EDUCATION

\begin{abstract}
This paper is a review who discusses how the domain of music has been influenced by cognitive psychology, forming the discipline of music psychology, or as some authors call music cognition. This interdisciplinary approch brought some advances in understanding how the human mind relates to music. Also, recent research in music cognition may contribute to music education as a whole. In this sense, the literature has pointed to sociocultural influence in informal learning and the developmente of cognitive skills multimodal with respect to formal music education. We conclude that music education must take into account the advances in cognitive science and rethinking integrating new forms of teaching that span cognition as a whole.
\end{abstract}

Keywords: music, music psychology, music education. 
No início do século XX com o desenvolvimento da Psicologia e notadamente da Psicologia Cognitiva mudou-se o rumo das pesquisas musicais. De fato, entender os efeitos da música sobre o homem sem compreender como a mente humana funciona não faz sentido. Por isso, a música se aproximou da psicologia, e alguns questionamentos sobre música e cérebro começaram a ser pesquisados cientificamente sob o olhar deste novo paradigma.

Então, o que é música?

Segundo Bohumil Med (1996) música é "a arte de combinar os sons simultânea e sucessivamente, com ordem, equilíbrio e proporção do tempo" (Med, 1996, p.11). Além disto, este autor aponta as principais características do som que são altura, duração, intensidade e timbre. Nesse sentido, a altura do som diz respeito à velocidade da frequência das vibrações. Isto significa que quanto maior a altura, maior o número de vibrações e consequentemente o som será mais agudo. Para não músicos um erro frequente é o de confundir a altura com a intensidade, em outras palavras, com o volume sonoro. Dessa forma, a intensidade caracteriza a amplitude das vibrações sonoras "determinada pela força ou pelo volume do agente que as produz" (ibidem, p. 11). O timbre é o que diferencia o som de acordo com seu emissor, por exemplo, o som da uma voz de uma pessoa com a voz de outra, ou com um instrumento musical qualquer. Ou seja, é a "cor" do som que é derivada "da intensidade dos sons harmônicos que acompanham os sons principais" (ibidem, p. 12). Já a duração, se relaciona com a extensão e o tempo do som emitido.

Maura Penna (2010) define a música como "uma forma de arte que tem como material básico o som". Além disto, ela argumenta que esta forma de linguagem artística é uma construção histórico-cultural. Assim, ela deixa claro que a música como linguagem não se caracteriza como linguagem universal, pode ser que seja um fenômeno universal, porém difere em cada cultura que se desenvolve como salienta a autora: 
Se a música fosse uma linguagem universal, seria sempre significativa para qualquer pessoa - isto é, qualquer música seria significativa para qualquer pessoa -, independentemente da cultura, e, desse modo, a estranheza em relação à música do outro não existiria (Penna, 2010, p. 24).

Já o compositor e educador canadense R. Murray Schafer (1986) define a música como sendo "uma organização de sons (ritmo, melodias, etc.) com a intenção de ser ouvida" (p. 35). Nesse sentido, ele argumenta que as antigas definições de música hoje em dia não cabem mais devido a expansão, entre outros, dos horizontes musicais com o desenvolvimento de novos instrumentos, procedimentos aleatórios, música eletrônica, música concreta e nova estética musical. Como aponta o autor: "hoje todos os sons pertencem a um campo contínuo de possibilidades, situado dentro do domínio abrangente da música" (Schafer, 1986, p. 121).

Por fim, o pesquisador lan Cross (2001) argumenta que a música tem características universais construídas de forma natural pelas sociedades humanas. Nesse sentido, ele aponta diferentes caminhos na definição da música, como som e movimento, a heterogeneidade dos significados musicais, a interação social que dá significados para cada cultura. Assim ele define música: “Música pode ser definida como atividades temporalmente padronizadas humanas em âmbito individual e social que envolve a produção e percepção de sons e que não tem referencial consensual fixo assim como eficácia evidente (Tradução dos autores) (Cross, 2001, p. 4). ${ }^{1}$

Portanto, podem-se sintetizar estas diferentes definições de música para conceituar um denominador comum que auxiliará a melhor compreender as pesquisas em cognição que tratam da música. Nesse sentido, música é uma organização de sons para serem ouvidos, uma linguagem socialmente construída. Embora sendo uma manifestação artística universal, sua linguagem varia de cultura a cultura. Por isso, as pesquisas realizadas no campo da cognição musical

\footnotetext{
${ }^{1}$ Music can be defined as those temporally patterned human activities, individual and social, that involve the production and perception of sound and have no evident and immediate efficacy or fixed consensual reference.
} 
tratam usualmente da música ocidental. Isto é importante enfatizar para deixar claro o objeto de estudo deste trabalho.

\section{O desenvolvimento da psicologia da música}

Ilari (2010) argumenta que Miller nomeou de revolução cognitiva as mudanças que ocorreram na década de 50, com o nascimento das ciências cognitivas, como por exemplo, as neurociências, a computação e com o a fixação e valorização de áreas de conhecimento como a antropologia, a psicologia e a linguística. Nesse sentido, o pensamento de Jean Piaget (1896-1980) sobre como as crianças aprendem, as ideais de Noam Choamsky (1928) sobre a linguagem e as descobertas sobre neurônios e inteligência artificial fizeram com que o conceito de mente fosse visto como um sistema complexo "(o hardware) com adaptações específicas ao contexto (o software), que precisava de esforços interdisciplinares para ser investigado" (p. 24) e certamente modificaram os rumos da nova psicologia da música.

Gjerdingen (2002) também destaca que os livros Emotion and meaning in music de 1956 de Leonard Meyer e o La perception de la musique de 1957 de Robert Francès e Les structures rythmiques (1956) de Paul Fraisse (1911-1996) influenciaram os pesquisadores da década de 60, fazendo com que as pesquisas nesse campo se focassem na percepção de padrões em melodias como, por exemplo, Diana Deutsch (1938) que pesquisou sobre a melodias musicais e memória. Posteriormente, ela também contribui publicando o importante livro Psychology of Music (1982) e fundou o periódico Music Perception. O autor também salienta que W. Jay Dowling (1941) contribuiu com a psicologia da música com sua publicação Music Cognition (1986).

Ilari (2010) aponta que nas décadas de 80 e 90 aconteceu notável avanço na área da psicologia da música, com a publicação de obras de referência como, por exemplo, A generative theory of tonal music de Fred Lerdahl e Ray Jackendoff (1983); The developmental psychology of music de David J. Hargreaves (1984), The musical mind de Sloboda (1983), entre outros. Ela também salienta a 
importância dos periódicos sobre psicologia da música, como o Psychology of Music (1972) pelos ingleses e os periódicos americanos Psychomusicology (19832001) e Music Perception (1983).

\section{A cognição musical na atualidade}

Cognição vem do termo latim cogitare que significa "pensar" como Marothy (2000) aponta. Nesse sentido, a cognição musical envolve o estudo de como o cérebro humano estabelece conceitos, se relaciona com a música, e especificamente com suas formulações verbais. Este autor sugere que a cognição musical envolve a integração de diversas áreas do conhecimento já que a música é uma experiência estética que envolve nossos sentidos e proporciona um "sentir". Assim, ele argumenta que sentir não é necessariamente o oposto de pensar. Por esse motivo, o estudo da cognição musical é um processo complexo que envolve diversas áreas do conhecimento como a psicologia cognitiva, neurobiologia, musicologia, entre outros.

Day (2004) salienta que a cognição musical busca entender como a experiência musical se dá tanto no sentido psicológico como fisiológico já que, por exemplo, duas pessoas que assistiram ao mesmo concerto terão impressões tão diferentes a respeito deste que se pode duvidar se assistiram ao mesmo evento. Ele também aponta que a cognição observa a experiência musical como algo percebido, ou seja, passa necessariamente pelo aparato sensorial, neste caso pela audição.

Porém, o autor destaca que a cognição musical não envolve somente os processos mentais relativos à escuta musical, mas também se abarcam outros aspectos como a memória musical, os estudos sobre preferências musicais, entre outros, que contemplam áreas como a teoria musical, as neurociências e a psicologia cognitiva, o que implica numa grande interdisciplinaridade. Assim, a cognição musical lida com os processos mentais adjacentes das experiências musicais como, por exemplo, a improvisação, composição, e performance e trás questionamentos relevantes a respeito da mesma. 
Day (2004) também argumenta sobre o recém-delineamento da cognição musical como disciplina que apesar de ter suas raízes teóricas na psicologia do séc. XIX se formou nas últimas décadas com a fundação da Society for Music Perception and Cognition e com o lançamento do periódico Music Perception ambos em 1983. O autor também destaca que a primeira conferência internacional sobre cognição e percepção musical aconteceu somente em 1990.

Daniel Levitin (2006) concorda com os autores acima e aponta que as recentes pesquisas em percepção e cognição musical buscam responder a questões como, por exemplo, o que faz com que uma pessoa escute uma peça musical de uma forma e outra que escutou a mesma obra, aparenta ter escutado algo completamente diferente. Porque algumas pessoas dão tanta importância para a música e outras não? Enfim, muitos questionamentos sobre a cognição musical estão sendo feitos e o autor também destaca a interdisciplinaridade desse domínio do conhecimento. Assim, a cognição musical dialoga com outras áreas como a psicologia cognitiva, as neurociências, a computação, educação, entre outros. Citando Levitin:

Se todos nós ouvimos as coisas da mesma maneira, fica difícil compreender por que a Madonna de uma pessoa é o Mozart da outra. Contudo, se cada um de nós ouve as coisas de maneira diferente, como explicar o porquê de certas peças musicais serem populares para quase todas as pessoas? Por que é que algumas pessoas na nossa cultura são movidas pela música e outras não? Para algumas, um dia sem música é impensável; a música as acompanha quando acordam, tomam banho e comem, no carro a caminho do trabalho, e como uma espécie de fundo acústico enquanto trabalham. A música também cria um clima para os encontros românticos, e dá energia aos exercícios físicos. A música é usada em épocas de guerra para incentivar a solidariedade patriótica e para sincronizar a infantaria, nos momentos de tristeza como consolação, desde solenes até os de júbilo. O status único da música na vida do ser humano é marcado por sua onipresença e antiguidade (Levitin, 2006, p. 25).

Para Ilari (2010), as definições em torno da cognição musical ainda estão em processo de construção, por isso existem diferenças conceituais que "estão longe de serem consensuais" já que diferentes áreas do conhecimento contribuem para o desenvolvimento da mesma. Também ela destaca que a partir da década 
de 1980 o termo psicologia da música foi substituído pelo termo cognição musical, "sobretudo em estudos referentes ao processamento de informações musicais pelo adulto com audição típica" (p. 27). Assim, ela argumenta sobre esta mudança de nomenclatura que o teórico Gjerdingen aponta, devido à relação de diferentes "subáreas" da psicologia que se aproximam da música, como é o caso da musicoterapia, a psicologia social, a psicologia das emoções, a psicologia da educação, entre outros.

Contudo, Levitin (no prelo) define a psicologia da música de forma diversa. Para ele os focos das pesquisas desta disciplina estão nas operações mentais, como por exemplo, as que ocorrem durante uma audição, práticas musicais, na composição e durante a dança (provocada pela música). Assim, a psicologia da música tem como base outras disciplinas da psicologia, isto é, da psicologia cognitiva, psicologia aplicada, psicologia social, psicologia do desenvolvimento humano, entre outras, assim como o conhecimento das ciências cognitivas, "da música e das pesquisas musicais realizadas pelas ciências da vida, ciências sociais e outras humanidades". Dessa forma, a cognição musical para este autor é uma subárea da psicologia da música e não significa de forma alguma ser sinônimo da mesma, pois aborda com abordagem experimental controlada como o sujeito percebe, interpreta e se recorda da música.

Além disto, o autor destaca o crescimento atual da psicologia da música com o aumento substancial das pesquisas que chegaram ao número de 700 publicações no ano de 2006. Levitin (no prelo) atribui este crescimento a interdisciplinaridade crescente entre as disciplinas acadêmicas, ao movimento de valorização da psicologia cognitiva nos anos 60 e ao desenvolvimento de novas tecnologias que facilitam a manipulação do som. Dessa forma, o autor aponta as principais linhas de pesquisa da psicologia da música. Sendo a cognição musical uma das linhas da psicologia da música. Citando o autor:

As linhas principais de pesquisa incluem: (1) percepção e cognição (por exemplo, os limites da percepção humana, as menores diferenças melódicas perceptíveis de altura, intensidade, etc; memória para os atributos musicais, como melodia, ritmo, timbre, etc; atenção e organização perceptual incluindo a junção/separação de vozes e instrumentos), (2) desenvolvimento (mudança de como os comportamentos musicais mudam ao longo da vida), 
(3) execução, planejamento do desenvolvimento motor, e aquisição de altos níveis de execução musical, (4) avaliação das habilidades musicais; (5) o papel da música no cotidiano, (6) desordens no processamento musical (7), estudos apontando semelhanças e diferenças culturais, (8) o impacto da música em domínios não musicais (9), educação (a melhor forma de ensinar música), e (10) bases biológicas e evolucionárias da música. (Tradução dos autores) (Levitin, no prelo, p.1). ${ }^{2}$

Levitin (no prelo) também argumenta que os pesquisadores da área estão se voltando para questões relativas às emoções provindas da audição musical, assim como comparam a música com a linguagem, e também, devido aos avanços tecnológicos em neuroimagens se voltam para a observação de como a música se processa no cérebro. Contudo, o autor salienta que a errônea vinculação nos meios de comunicação de que a escuta passiva de música clássica, especificamente a de Mozart, aumentaria a inteligência é exagerada. Ele também destaca que pesquisas demonstram efeitos extramusicais da audição, por exemplo, de diminuir a dor e o estresse em pacientes, devido ao fato de a música distrair e aumentar os níveis de endorfina e dopamina aumentando assim a sensação de bem estar e o sentimento de inclusão social.

Outro ponto que Levitin (no prelo) destaca é que as pesquisas neurológicas relativas à percepção e cognição musical são recentes e ainda trazem muitos questionamentos. Ele também destaca que muitas questões levantadas notadamente pelos teóricos da Gestalt, como por exemplo, de como melodias transpostas para outras tonalidades são reconhecidas continuam ainda sem solução. Assim como, da conservação do pulso, apesar de haver em certas musicas diferentes dinâmicas, outro ponto é a questão de como o ser humano consegue separar e escutar as diferentes vozes presentes na música, também a questão de

\footnotetext{
2 Prominent lines of research include: (1) perception and cognition (e.g. perceptual thresholds - the smallest perceptible differences in pitch, loudness, etc.; memory for musical attributes such as melody, rhythm, timbre, etc.; attention and perceptual organization including fusion/separation of voices and instruments); (2) development (how music behaviors change across the life-span), (3) performance, motor planning, and the attainment of expertise, (4) assessment and predictors of musical ability; (5) the role of music in everyday life, (6) disorders of music processing, (7) crosscultural similarities and differences, (8) the impacto of music training on nonmusical domains, (9) education (how best to teach music), and (10) the biological and evolutionary basis of music.
} 
como se criam e se resolvem expectativas proporcionadas pela música, estas questões dentre muitas outras ainda permanecem obscuras.

Apesar disso, Maróthy (2000) faz uma ressalva em relação à psicologia experimental aplicada à música, pois o fato de procurar recriar em laboratório situações da vida real de forma artificial pode reduzir algo que é complexo como a música. Nesse sentido, ele argumenta sobre a diferença entre os psicólogos que vem os seres humanos como "meros receptores" e alguns pesquisadores que reduzem por sua vez a complexidade da música para poder isolar variáveis e acabam negligenciando aspectos importantes da mesma. Como destaca o autor:

Pior do que isso, os sujeitos estão sendo examinados em contextos experimentais, ao invés de situações realmente musicais, as relações entre os sons que estão sendo apresentadas aos sujeitos são semelhantes a exemplos de uma lição de solfejo. Qualidades por trás da "melodia" estão sendo negligênciadas, sons de piano, tons senoidais ou outros como, na melhor das hipóteses, sons sintéticos de baixa qualidade são suficientes. Perguntas como "Você considera isso como um acorde de dó ou ré?" São típicas. (Tradução dos autores) (Maróthy, 2000, p. 120) ${ }^{3}$

Maróthy (2000) salienta também que a música é resultado de ondas de vibrações que se propagam no ar, por isso, antes de ser observada a música precisa ser produzida. Nesse sentido, ele coloca que os sons precisam ser produzidos de forma regular e sincronizada para serem percebidos, assim como são sincronizados os impulsos dos neurônios nos seres humanos. Dessa forma, a percepção musical de um ouvinte é mais intensa se o sujeito estiver sincronizado com a fonte produtora do som. Ele também aponta que as sensações advindas da música não se restringem nas sensações mentais, más também são fruto da cadeia neural que envolve o corpo "como um todo" durante as atividades musicais. Portanto, perceber e fazer música desencadeia conforme o autor sugere uma sincronização rítmica que atinge o corpo na sua totalidade. Fracionar o fenômeno musical é de certa forma para este autor sinônimo de retirar o viés artístico da

3 Worse than that, subjects are examinated in experimental rather than really musical situations, sound relations being presented to them in examples similar to a lesson of solfeggio. Qualities beyong "pitch" being neglected, piano sounds or even sine tones or else, in the Best case, low dimension are synthetic sounds suffice. Questions like "Do you regard this tone as a C sharp or a D?" are typical. 
música. Nesse sentido, ele sugere que pesquisas em cognição musical levem em conta a complexidade do que se mensura, por exemplo, com neuroimagens “Gravações da atividade do cérebro (EEG), tensão muscular (EMG), respiração, plestimogramas de dedos e resposta galvânica da pele (GSR) durante a audição musical." (Tradução dos autores) (Maróthy, 2000, p. 122). ${ }^{4}$

\section{A cognição musical no Brasil}

No Brasil as pesquisas em cognição musical seguem a tendência mundial de crescimento, porém em proporções menores. Existem atualmente 10 grupos de pesquisa registrados no CNPQ, dos quais, mais da metade foram formados entre 2010 e 2011. Aliás, a Associação Brasileira de Cognição \& Artes Musicais foi formalizada em meados de 2006. Esta promove o Simpósio de Cognição e Artes Musicais (SIMCAM) que está atualmente na sua décima edição (a última aconteceu em 2014), e contribui também para a promoção e o fortalecimento da área.

Contudo, Ilari (2010) ressalta que a disciplina da cognição musical ainda carece de literatura especializada no Brasil. Poucas obras de referência como às citadas nesse artigo foram traduzidas para o português. Esta, entre outras dificuldades como, por exemplo, o financiamento das pesquisas, a falta de equipamentos de última geração, entre outros, assolam os pesquisadores brasileiros.

\section{Contribuições da psicologia da música para a Educação}

Para David J. Hargreaves (1986) o termo cognição musical diz respeito à percepção musical, a linguagem musical, o pensar e memorizar a música, a atenção, as habilidades musicais e o aprendizado musical. Nesse sentido, deve-se destacar que para este autor habilidades e aprendizado apesar de serem termos

\footnotetext{
${ }^{4}$ Recordings of the activity of the brain (EEG), muscle tension (EMG), breathing, finger oscillogramme and galvanic skin response (GSR) while listening to music"
} 
próximos são diferentes. A ênfase da cognição musical está nas operações mentais internalizadas, ou seja, nas representações mentais dos sujeitos que planejam comportamentos sequenciados em suas mentes o que evidência de certa forma a aproximação com a educação.

Ele aponta também que algumas pesquisas focaram-se em questões sobre o desenvolvimento musical em crianças. Nesse sentido, Miller (1983) se focou em pesquisar como ocorre o desenvolvimento da memória, do pensamento lógico, da resolução de problemas, e de como as crianças representam informações. Assim, o desenvolvimento é sinônimo de aprendizado e é colocado por ele como a aquisição de habilidades, citando o autor: "O desenvolvimento é concebido, de acordo com este ponto de vista, na aquisição de habilidades cognitivas específicas, e também no aumento da capacidade de processá-las." ${ }^{5}$ (Tradução do autores) (Hargreaves, 1986, p. 17).

John A. Sloboda (2008) concorda com Hargreaves no que tange a aquisição de habilidades musicais. E argumenta também que é preciso aproximar a música da psicologia cognitiva, pois "a maioria de nossas respostas à música são aprendidas" (Sloboda, 2008, p. 6). Nesse sentido, se a música emociona ela passa necessariamente por um "estágio cognitivo que envolve a formação de uma representação interna, simbólica ou abstrata da música" (ibidem, p. 3) e é socialmente apreendida. Dessa forma, a cultura tem papel preponderante no desenvolvimento de habilidades musicais.

Assim, este autor salienta que o processo de aprendizagem é caracterizado pela forma como representamos a música em nossas mentes, e se dá primeiramente por meio da enculturação $0^{6}$ durante a infância e posteriormente pela aquisição e treinamento de habilidades específicas. Citando Sloboda:

A primeira é a enculturação desenvolvimentista, isto é, aquele, aprendizado que resulta de nossa exposição durante a infância aos produtos musicais comuns de nossa cultura, juntamente com a aquisição de habilidades simples, tais como a habilidade de reproduzir canções curtas. De maneira

\footnotetext{
5 "Development is conceived, from this point of view, in terms of the acquisition of particular cognitive skills, and of increases in the capacity and rate of processing"

${ }^{6}$ A enculturação é fruto da exposição das crianças aos meios socioculturais e constitui uma forma primária de aprendizado inconsciente de determinados aspectos da música.
} 
geral, o conhecimento adquirido nesta fase não resulta de uma aprendizagem ou de um esforço autoconscientes. Ao contrário, as crianças simplesmente adquirem conhecimentos através de suas experiências sociais no dia-a-dia. Em consequência disso, tal conhecimento tende a ser universal em uma determinada cultura, e constitui a base sobre a qual outras habilidades especializadas serão construídas. A segunda fase é a aquisição de habilidades específicas através do treinamento. Estas habilidades não são universais em uma determinada cultura; são aquelas que transformam os cidadãos comuns em "músicos" (Sloboda, 2008, p. 10).

Além disto, ele destaca que na fase do aprendizado informal por meio da enculturação não há esforço autoconsciente por parte das crianças exceto se estas estejam envolvidas em situações de aprendizado formal de música. Mesmo assim. as crianças memorizam canções sem que haja necessariamente a vontade de que memorizem. No que tange a segunda fase que diz respeito à aquisição e o desenvolvimento de habilidades musicais através do treino, fica claro, que o esforço autoconsciente está presente. Além, do uso de métodos adequados de ensino que motivem e sejam mais eficazes para cada pessoa. Por isso, a compreensão dos processos psicológicos envolvidos na aprendizagem é fundamental para que não se estabeleçam receitas infalíveis de ensino e é preferível que o professor "faça uso de seus próprios métodos, adequando-os às situações e aos alunos com quem trabalha" (p. 261) para ter êxito.

Hargreaves (2003) destaca o poder que a música tem de influenciar as pessoas, notadamente no campo da educação, como por exemplo, com o uso consciente de determinadas canções para mudar estados emocionais de adolescentes do ensino médio. Os comportamentos musicais são, para este autor, construções socioculturais e abarcam diferentes níveis como as diferenças individuais que abarcam o gênero, idade e personalidade. Assim como as interações interpessoais que influenciam os gostos e preferências das crianças. Também, o nível institucional está presente nos lares, nas escolas, na comunidade e organizações musicais. E, por fim, o nível cultural presente principalmente na mídia, e nas tradições culturais nacionais e regionais.

Todavia, ele aponta a mudança de paradigma na educação que deve levar em conta aspectos físicos e sociais para o desenvolvimento de conhecimentos. Dessa forma, este autor sugere que o referencial piagetiano deve ser substituído 
pelo vygotskiano, pois se aprende música na interação entre pares, nos âmbitos descritos acima, ou na relação professor/aluno. Já para este autor, a teoria dos estádios cognitivos de Piaget apesar de ser útil para saber o que as crianças são capazes de aprender de acordo com sua faixa etária, não tem nada de social.

Hargreaves (2003) aponta que a psicologia da música nunca esteve tão próxima da educação musical, pois o desenvolvimento da educação musical passa pelo desenvolvimento sociocultural que está interligado com a psicologia social, como salienta o autor:

A incorporação da perspectiva social, cultural em música e psicologia é acompanhada pelo reconhecimento do amplo contexto social e cultural em educação musical, tal como a psicologia social, da música e da educação musical que tem bases conceituais sólidas. (Tradução dos autores) (Hargreaves, 2003, p. 161). ${ }^{7}$

No entanto, cabe aqui relembrar que a posição de Jean Piaget difere substancialmente da apontada por Hargreaves (2003). O desenvolvimento mental para Piaget (2003) engloba diversos fatores como: a maturação, ou seja, o crescimento orgânico do sujeito, experiência adquirida na interação com objetos, nas “interações e transmissões sociais" (Piaget, 2003, p. 138) e por fim o processo de equilibração. ${ }^{8}$ Também, este autor destaca que as interações sociais, afetividade e processos cognitivos são indissociáveis. Assim, a afetividade é o combustível da interação social que por sua vez pode ter dois vieses: relação entre pares ou crianças e adultos com cunho construtivo e relações entre crianças e adultos como fonte de aprendizado, citando Piaget:

\footnotetext{
7 "The incorporation of the social cultural perspective in music and music psychology is matched by the acknowledgment of the broader social and cultural context in music education, such that a developmental social psychology of music and music education has some firm conceptual foundations".

${ }^{8}$ Segundo Piaget o mecanismo de equilíbrio é constituído pelos processos de assimilação e acomodação. Conceitos estes inspirados na Biologia. O sujeito assimila, ou seja, incorpora determinado conhecimento que pode trazer contradições ao seu ponto de vista. Então, o sujeito fica em desequilíbrio cognitivo momentâneo. Posteriormente, ao integrar este novo conteúdo a sua estrutura pré-existente, o sujeito chega ao equilíbrio cognitivo. A figura da espiral pode ilustrar o mecanismo da equilíbrio que é um processo contínuo durante toda a vida.
} 
Notemos primeiro que o termo "social" pode corresponder a duas realidades bem distintas, do ponto de vista afetivo, como já o acentuamos ao estudar o ponto de vista cognitivo: há, primeiro, as relações entre a criança e o adulto, fonte de transmissões educativas e linguísticas das contribuições culturais, do ponto de vista cognitivo, e fonte de sentimentos específicos e, em particular, dos sentimentos morais (...), do ponto de vista afetivo; e há, em seguida, as relações sociais entre as próprias crianças, e em parte entre crianças e adultos, mas como processo contínuo e construtivo de socialização e não mais simplesmente de transmissão em sentido único (Piaget, 2003, p. 105).

Sloboda (2007) por sua vez, reitera que todas nossas relações com a música como, por exemplo, escutar ou executar música, são comportamentos apreendidos culturalmente, e que entender os mecanismos cognitivos envolvidos neste desenvolver de habilidades, passa necessariamente, pela compreensão do pensamento humano, isto é, pela cognição.

Susan Hallam (2001), por sua vez, destaca que aprender é um processo natural no ser humano e que existem diversas formas para que o aprendizado ocorra. Em alguns casos, mesmo com dificuldades aprende-se, para isto, é necessário esforço e tempo. Também, é preciso apontar a complexidade do processo de aprendizado e levar em conta aspectos como: características do aprendiz, o meio no qual ocorre o aprendizado, o processo de aprendizado e seus resultados, entre outros.

Entretanto, Hallam (2001) aponta que as pesquisas sobre aprendizado musical se dividem em duas categorias; estudos que abordam a enculturação, ou seja, sobre o desenvolvimento de processos que resultam em capacidades primitivas musicais geradas a partir de experiências culturais resultando em mudanças cognitivas. E, pesquisas sobre o desenvolvimento de habilidades musicais (generative skills), ou seja, experiências que ocorrem num meio educacional específico, onde somente alguns indivíduos da sociedade participam e desenvolvem-se. Dessa forma, há presença deliberada de esforço e de metodologias de ensino. Cabe salientar aqui a convergência das ideias desta autora com as de Sloboda $(2007,2008)$ que estão abarcadas no paradigma da cognição musical.

Hallam (2011) também aponta que o conceito de habilidade musical se desenvolveu em paralelo com o desenvolvimento da psicologia na metade do 
século XX. A psicologia buscou categorizar com testes psicológicos indivíduos de acordo com seus níveis de inteligência que eram geneticamente transmitidos e imutáveis. No meio musical, testes de habilidade, ou de talento musical buscavam auxiliar os professores de música para a seleção de aprendizes, por exemplo, os testes de Revez (1953), Seashore (1960), Wing (1961), Gordon (1963) e Bentley (1966).

Contudo, Hallam (2010) aponta que as pesquisas atuais vêm desconstruindo a utilidade dos testes de habilidades musicais do passado já que evidências comprovam que o desenvolvimento musical está atrelado ao número de horas de prática, ou de estudo de qualidade e não a herança genética do sujeito. Obviamente que não basta estudar de qualquer forma para o desenvolvimento contínuo de habilidades musicais. Aliás, o excesso de prática pode até levar os estudantes de música a desistir, como algumas pesquisas destacam Wagner (1975, apud Hallam, 2011) e Zurcher (1972, apud Hallam, 2011). Outros fatores como a motivação, a autorrealização, interação social, apoio dos pais, entre outros, tem se mostrado mais importantes para o desenvolvimento de habilidades musicais, como destaca a autora:

Além disso, as habilidades podem ser desenvolvidas através de práticas lúdicas ou tocando em grupos, e não somente pela prática deliberada. Fatores sociais, como o apoio dos pais, a personalidade do professor e interações entre pares também mostraram-se mais relevantes do que a quantidade de prática para alcançar altos níveis de execução musical. (Tradução dos autores)(Hallam, 2011, p. 310). ${ }^{9}$

Além disto, deve-se levar em conta que a habilidade musical é um conjunto de habilidades cognitivas e está muito além do desenvolvimento de uma habilidade específica. Segundo a autora, para se desenvolver musicalmente é necessário o desenvolvimento multimodal de diversas habilidades cognitivas como, por exemplo, habilidades motoras, musicalidade, habilidades para o

\footnotetext{
9 "In addition, skills can be developed through playful practice and playing in groups, not only through deliberate practice. Social factors such as parental support, teacher's personality and peer interactions have also been shown to be more important than amount of practice time in achieving a high level of musical performance".
} 
aprendizado, e, sobretudo a criatividade. Também, é necessário observar os pontos fortes e fracos de cada aprendiz assim como aspectos como motivação e autodisciplina. E, sobretudo, destacar a leitura musical que envolve o uso concomitante de diversas habilidades cognitivas.

Também, Levitin (2011) destaca que o estudo científico acerca do desenvolvimento de habilidades que exigem alta qualificação, ou seja, alto nível de especialização vem sido investigado pelas ciências cognitivas e o domínio da música segue esta tendência. Nesse sentido, este autor cita a pesquisa de Anders Ericsson $(1991,1996,2005)$ que trata a questão das habilidades musicais como um problema de psicologia cognitiva "que diz respeito à maneira como os seres humanos adquirem determinado grau de especialização" (p.222). Assim, argumenta-se que o esforço é um dos fatores determinantes para se tornar especialista em qualquer coisa. O estudo aponta também que são necessárias aproximadamente dez mil horas de prática para chegar ao nível de alta qualificação em qualquer domínio. Isto equivale a aproximadamente vinte horas semanais de estudo durante dez anos. Como coloca Ericsson:

(...) De acordo com esta regra, nem mesmo os indivíduos "talentosos" podem alcançar desempenho a nível internacional sem aproximadamente 10 anos de preparação (...). Na verdade, as diferenças individuais no que se refere à quantidade de prática deliberada são determinados a partir do treino diário e mostraram estar relacionados com o nível de desempenho atingido por músicos profissionais e atletas (...). Uma análise dos padrões de prática e descanso dos executantes indicou que a quantidade máxima de treino suportada diariamente, durante anos, sem serem levados à exaustão e abandonos, foi em torno de quatro horas diárias. (Tradução dos autores) (Ericsson; Lehmann, 1996, p. 278-279). ${ }^{10}$

Ericsson (1991, 1996, 2005) também argumenta que as pesquisas relativas ao aprendizado e ao treino de habilidades, sendo elas em domínios como

10 (...) According to this rule, not even the most "talented" individuals can attein international performance without aproximately 10 years of preparation (...). In fact, individual differences in the amount of deliberate practice, determined from diaries and retrospective estimates, were shown to be related to the level of performance atteined by expert musicians and athletes (...). An analysis of these performers's daily patterns of practice and rest indicated that their maximum amount of fully concentrated training that they could soustain every day for years without leading to exhaustion and burning-out was around four hours a day. 
a música ou esportes, usa-se o termo prática deliberada (deliberate practice) para designar atividades individuais acompanhas por professores ou por treinador para aprimorar aspectos específicos por meio da repetição e refinamento das habilidades. Nesse sentido, para melhor proveito do feedback ${ }^{11}$ por parte dos aprendizes é necessário concentração e esforço. Por fim, Ericsson (2005) destaca que é necessário acumulo de conhecimento para alcançar altos níveis de performance e o desenvolvimento e aquisição de representações mentais como mecanismos que possibilitem melhor controlar, planejar e raciocinar sobre a melhor forma de manter e aprimorar as habilidades cognitivas.

\section{Considerações finais}

A literatura cognitiva aponta, por um lado, a influência cultural na assimilação do conhecimento musical que é apreendido de forma individual de forma inconsciente durante as interações entre pares, e ou, com as produções culturais de cada sociedade. Por outro lado, os indivíduos que deliberadamente querem desenvolver as habilidades musicais se deparam com o ensino de música formal ou informal. Este deve levar em conta que o ensino da música abarca o desenvolvimento de habilidades cognitivas multimodais com crescente complexidade, como por exemplo, a leitura musical que necessita a coordenação de diversas habilidades (motoras, cognitivas, representacionais, entre outros).

Dessa forma, compreender como se desenvolvem as habilidades cognitivas em experts de nível internacional, que estão relacionadas de certa forma ao tempo gasto com a prática e com o aprimoramento das mesmas, pode ajudar a identificar a melhor forma de ensino e treino efetivo de músicos iniciantes. Aspectos como a motivação, experiência prévia, relação professor/aluno, afetividade, concentração, e principalmente o esforço deliberado são pré-requisitos obrigatórios a serem levados em conta para um programa educacional efetivo que busque a melhor forma de construção de conhecimento e o desenvolvimento e treino de habilidades cognitivas multimodais.

\footnotetext{
${ }^{11}$ Feedback diz respeito ao retorno dado ao aluno pelo professor ou treinador.
} 
Conclui-se então que a educação musical deve levar em conta os avanços da cognição musical buscando integrar e repensar novas metodologias de ensino que abarquem a cognição como um todo, lembrando que a música como linguagem socialmente construída já está presente na mente de todos os indivíduos de dada sociedade. Para que os sujeitos desenvolvam-se musicalmente é necessário esforço deliberado para motivarem-se a treinarem habilidades cognitivas que estão interligadas a energia da afetividade proveniente da evocação de profundas emoções fruto da mente musical.

\section{Referências}

ABBAGnANO, N. Dicionário de Filosofia. São Paulo: Martins Fontes, 2000.

CROSS, I. Music, cognition, culture, and evolution. In: PERETZ, I. \& ZATORRE, R. (Orgs.) The cognitive neuroscience of music. Oxford University Press, 2003, p.5778.

ERICSSON, K.A. \& SMITH, J. Toward a general theory of expertise: prospects and limits. New York: Cambridge University Press, 1991.

ERICSSON, K.A. ; LEHMANN, A.C. Expert and exceptional performace: Evidence of maximal adaptation to task constraints. Annu. Rev. Psychol., 1996, p.273-305.

ERICSSON, K.A. Recent advances in expertise reserch: a commentary on the contributions to the special issue. Appl. Cognit. Psychol., 2005, p.233-241.

FONTERRADA, M. .T. de O. De tramas e fios: um ensaio sobre música e educação. São Paulo: Unesp, 2008.

GJERDINGEN, R. The psychology of music. In: CHRISTENSEN, T. (Org.). The Cambridge History of Western Music Theory. Cambridge: Cambridge University Press, 2002, p. 956-981.

HALLAM, S. 21th century conceptions of musical ability. Society for Education, Music and Psychology Research. 2010, p.308-330.

ILARI, B. Cognição musical: origens, abordagens tradicionais, direções futuras. In: ILARI, B.; ARAÚJO, R.C. (Orgs.). Mentes em música. Editora da Universidade Federal do Paraná, 2010, p. 11-33.

LEVITIN, D. J. Em busca da mente musical. In: ILARI, B. (Org.) Em busca da mente musical: ensaios sobre os processos cognitivos em música - da percepção à produção. Curitiba: Editora da Universidade Federal do Paraná, 2006, p. 23-44. . Psychology of Music. International Encyclopedia of Social Sciences. New York: Macmillan. No prelo. 
- A música no seu cérebro: a ciência de uma obsessão humana; tradução de Clóvis Marques. Rio de Janeiro: Civilização Brasileira, 2011.

MAROTHY, J. Cognitive musicology, praised and reproved. Studia Musicologica Academiae Scientiarum Hungaricae, v.41, n.1-3, p. 119-123, 2000.

MED, B. Teoria da música. Brasília: Musimed, 1996.

PENNA, M. Música(s) e seu ensino. Porto Alegre: Sulina, 2010.

PIAGET, J.; INHELDER, B. A psicologia da criança; tradução Octavio Mendes Cajado. Rio de Janeiro: Difel, 2003.

PLATÃO. A República. São Paulo: Editora Martin Claret, 2007.

SCHAFER, R. M. O ouvido pensante. Tradução Marisa Trench de O. Fonterrada, Magda R. Gomes da Silva, Maria Lúcia Pascoal. São Paulo: Unesp, 1991.

SLOBODA, J. A. A mente musical: psicologia cognitiva da música; tradução de Beatriz Ilari e Rodolfo Ilari. Londrina: Eduel, 2008.

, J. A.; LEHMANN, A. C.; WOODY, R. H. Psichology for musicians: understanding and acquiring the skills. Oxford University Press, 2007. 